Research Article

Check for updates

OPEN ACCESS

Received: Apr 12, 2019

Accepted: Jul 18, 2019

*Correspondence:

Jin-Ha Yoon

Department of Preventive Medicine, Yonsei University College of Medicine, 50 Yonsei-ro, Seodaemun-gu, Seoul 03722, Korea.

E-mail: flyinyou@gmail.com

Copyright (c) 2019 Korean Society of Occupational \& Environmental Medicine This is an Open Access article distributed under the terms of the Creative Commons Attribution Non-Commercial License (https:// creativecommons.org/licenses/by-nc/4.0/) which permits unrestricted non-commercial use, distribution, and reproduction in any medium, provided the original work is properly cited.

ORCID IDs

Sung-Shil Lim (iD

https://orcid.org/0000-0001-6733-7933 Jihyun Kim (D)

https://orcid.org/0000-0002-8071-3435 Jin-Ha Yoon (iD

https://orcid.org/0000-0003-4198-2955

Abbreviations

CESD: Center for Epidemiologic Studies Depression; OR: odds ratio; Cl: confidence interval.

Funding

This work was supported by the Korean Society of Occupational and Environmental Medicine fund.

\section{Depressive symptoms among dance artists in South Korea: balance between self- and social identity on job value}

\author{
Sung-Shil Lim (1) ${ }^{1,2,3}$, Jihyun Kim (10) ${ }^{1,2,3}$, Seahee Yune ${ }^{4}$, and Jin-Ha Yoon (1] ${ }^{1,2,3,5 *}$ \\ 'Department of Occupational and Environmental Medicine, Severance Hospital, Yonsei University College \\ of Medicine, Seoul, Korea \\ ${ }^{2}$ The Institute for Occupational Health, Yonsei University College of Medicine, Seoul, Korea \\ ${ }^{3}$ Department of Public Health, Yonsei University College of Medicine, Seoul, Korea \\ ${ }^{4}$ The Graduate School, Sangmyung University, Seoul, Korea \\ ${ }^{5}$ Department of Preventive Medicine, Yonsei University College of Medicine, Seoul, Korea
}

Background: The balance between self- and social identity on job value of Korean dance artists, considered as performing artists, was measured to investigate the relationship between balance and depressive symptoms.

Methods: Data of 139 dance artists were analyzed for depressive symptoms assessed by their responses to questionnaires from the Center for Epidemiologic Studies Depression (CESD) translated into Korean. The balance score of each aspect of social identity compared to that of self-identity on job value was measured and classified as lower, equal, or higher. Following a graphical approach, we performed locally weighted scatterplot smoothing algorithm, simple linear regression, and quadric equation regression.

Results: The mean of CESD was highest in the higher balance group and lowest in the lower balance group. There was a linear relationship between balance score and CESD regarding specific audience, unspecified audience, and unspecified public. Balance score showed no association with other aspects of social identity. In the balance score range of 1 or higher, it was associated with CESD with respect to artist colleague, unspecified audience, and unspecified public.

Conclusions: Dance artists should maintain a balance between self- and social identity in job value to prevent depressive symptoms.

Keywords: Depressive symptoms; Artists; Job identity; Self-identity; Social identity

\section{BACKGROUND}

Depression is one of the most prevalent diseases worldwide [1]. Depression-induced economic and work productivity loss brings serious social problems [2]. Depression is also known to be linked to various health-related risk factors such as new medical illness and chronic disability, objective as well as perceived poor health status, and past history of depression [3].

Work-related factors are also related to depression. For example, job strain, emotional labor, effort-reward imbalance, long working hours, night shift work, economic recession, 
Competing interests

The authors declare that they have no competing interests.

Availability of data and materials The datasets generated and/or analyzed during the current study are not publicly available since they are confidential but are available from the corresponding author on reasonable request.

Authors contributions

Conceptualization: Lim SS, Yoon JH; Data curation: Lim SS, Yoon JH; Formal analysis: Lim SS, Kim J; Supervision: Yoon JH; Validation: Yoon $\mathrm{JH}$; Writing - original draft: Lim SS, Kim J. and unemployment cause and aggravate depression [4-9]. However, there are relatively few studies on mental illness of workers in creative occupation. The nested case-control study using Swedish national registers reported that artists were more likely to suffer from mental illness, especially depression, unlike scientists (artistic occupations: odds ratio [OR], 1.07; 95\% confidence interval [CI], 1.04-1.10; scientific occupations: OR, 0.73; CI, 0.70-0.76) [10]. This might be attributed to artists' occupational characteristics. Values of an occupation in performance art are usually assessed by audiences, while values of scientific occupations might be evaluated by professional license, scientific papers or any results and inventions from scientific ability. In other words, artistic value is measured less objectively from the related social environment when compared to other occupational values.

The value of an artist's job performance can be measured by the degree of completion of the performance, artistic quality, creativity, originality, popularity, and so on. Art experts such as professors, members of boards, and senior artists assess artistic quality and degrees of completion. Artists' colleagues are also instrumental in enhancing an artist's reputation besides criticizing their performance. Hence, a part of the self-concept, or social identity, is formulated from social group evaluation [11]. Visual arts, including painting, create static art objects, and such artists do not frequently face direct evaluation from the public. However, in the performing arts, artists use their voice or their body to create art and express their art in front of live audiences. Hence, audience feedback becomes very important for measuring values of performing arts. In recent times, there are unspecified audiences evaluating performing arts with the development of mass media, internet, and social media, which might lead to artists' developing depressive symptoms [12].

Consequently, performance artists can recognize their job value from the concept of their occupational "social-self," the "looking-glass self," and the "presenting self" [13]. The socialself can often be threatened by the negative evaluation of social groups and the resulting social-evaluative threat [14] can cause a stress response that increases an artist's cortisol level [15] and induces psychological symptoms of anxiety and fear with diminished job performance [16]. Social evaluative threat interacts with the hypothalamus-pituitary-adrenal axis, and the response leads to depressive symptoms [17]. When artists give more weight to social group evaluation regarding their jobs when compared to their self-evaluation, they might be harmed by the social-evaluation threat. The amount of shift from the self- to the social group evaluation may relate to vulnerability even though they may not face direct social evaluation threat. Hence, we hypothesize that the amount of shift from self- to social evaluation regarding their job value can relate to depressive symptoms. In other words, the balance between self-identity and social identity regarding their job may be related to depressive symptoms.

Performing artists face a social evaluative threat from self, expert board members, colleagues, specific audience, unspecified audience, and unspecified public. Furthermore, economic reward is one of factors affecting job value from a business perspective. To construct a selfconcept about job value, a balance between self- and social identity is essential [11]. However, the balance between self- and other social identities was not studied for their relationship with depressive symptoms. In our study, Korean dance artists as performing artists were the participants, and we measured the balance between their self- and social identity to investigate its relationship with depressive symptoms. We hope our current study helps artists find a balance between self- and social identity to ensure their psychological health. 


\section{METHODS}

\section{Study participants}

Participants were recruited by 6 professional artists who had graduated from Sookmyung Women's University. Each professional artist distributed the questionnaire to their colleagues. In total, self-reported questionnaires from 150 dance artists were collected from 1 July 2017 to 30 August 2017. Among the potential participants, 1) 16 participants with missing values of sex, Center for Epidemiologic Studies Depression (CESD), and balance score (social identity and self-identity), 2) 2 participants with no experience of performance art on stage, and 3) 3 participants whose scores showed 3 standard deviation from the mean of the balance score were excluded. Finally, data of 139 participants were used in the current study.

\section{Self-reported questionnaires}

Basic characteristics such as age, sex, education, marital status, working institution status, type and of dance performed were surveyed. Depressive symptoms were assessed using a 20-item questionnaire from the CESD translated into Korean [18]. The CESD scale consists of 4 subscales including depressed effect (feeling sad, crying spells, not able to shake off the blues, depressed, lonely, fearful, and feeling of being a failure in life); positive effect (hopeful about the future, enjoying life, feeling good, and feeling happy); somatic symptoms (poor appetite, restless sleep, could not get going, difficulty in concentrating, everything seemed an effort, bothered by unnecessary things, and talking less than usual); and interpersonal problems (feeling of being disliked by people and considering people unfriendly).

In this study, the balance score of each social identity compared to the self-identity based on job value was defined by using the second step mentioned below. First, we analyzed the questionnaire as follow: "How much do the following factors influence you in determining the identity of your artistic work?." The factors for evaluation are self, money rewards, art experts, artist colleague, specific audience, unspecified audience, and unspecified public. Evaluation by unspecified audience and unspecified public indicated were assessment by audience whom artists had not known and by public who had observed dancers through media such as newspaper, TV or SNS, respectively. The response options are scored on a 5-point Likert scale with "not important," "slightly important," "moderately important," "important," and "very important" relating to scores 1, 2, 3, 4, and 5, respectively. Second, the score on each social category was divided by the score on self-evaluation to calculate the balance score. Hence, if the balance score of a category is 1 , it means that the artist is influenced as much by social identity as by self-identity.

\section{Statistical analysis}

The balance score of each social identity compared to self-identity based on job value was divided into 3 groups: lower (social identity < self-identity), equal group (social identity = self-identity) and higher (social-identity > self-identity). We conducted a 1-way ANOVA to explore between-group differences and a post hoc test to calculate between-group differences using Tukey's honest significance test, as shown in Fig. 1. As graphically shown in Fig. 2, we performed the locally weighted scatterplot smoothing algorithm (loess span $=1.00$ ), a widely used smoothing procedure [18], and simple linear regression between balance score of identity on job value and depressive symptoms (Fig. 2A). The optimal score on each social-identity compared to that on self-identity based on job value was calculated by min level quadric equation of regression model fitting in Fig. 2B. We also conducted piecewise linear regression at the breaking point of 1 of the balance score where social identity is equal to self-identity 

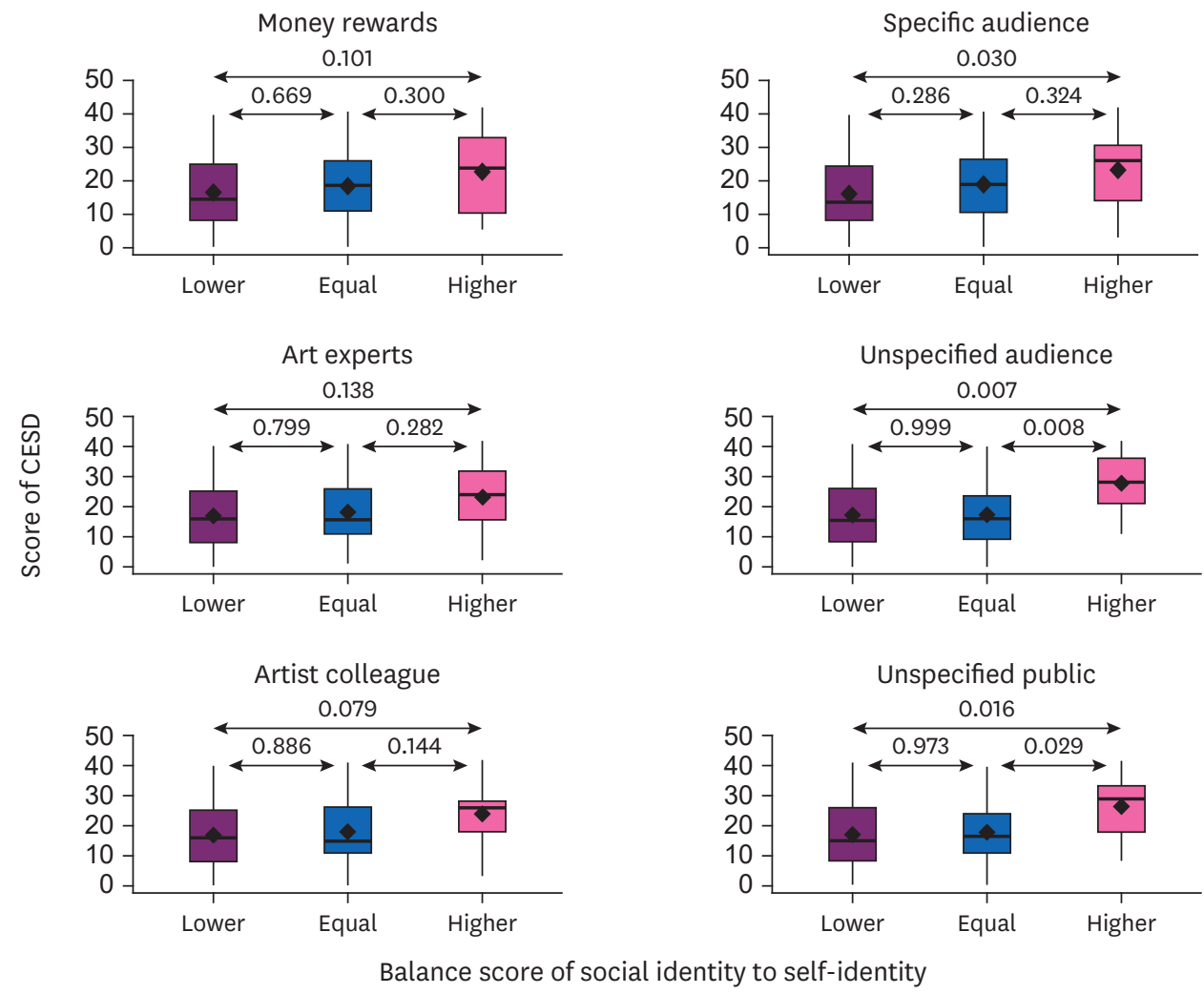

Fig. 1. The comparison of CESD among the group of balance score of identity on job value. Lower, Equal, and Higher indicate dancers with lower social-identity than self-identity, with social-identity with self-identity and with higher social-identity than self-identity on job value. The numerical values indicate the $p$-value from results of post hoc test between the group of balance score of identity on job value. Horizontal line and round point indicate the median and mean of CESD, respectively. Box indicates the inter-quartile range. CESD: Center for Epidemiologic Studies Depression.

based on job value. A $p$-value $<0.05$ was considered statistically significant. All analyses were conducted using R (R Foundation for Statistical Computing, Vienna, Austria) [19].

\section{Ethics statement}

Written informed consent was obtained from all participants, and the Institutional Review Board of the Yonsei University Health System approved this study (Y-2017-0030).

\section{RESULTS}

Table 1 shows the basic characteristics of the study participants. There were 139 dancers with a mean age of 31.84, consisting of $121(87.05 \%)$ females and $18(12.95 \%)$ males. Most of the dancers performed Korean dance (126 dancers, $90.65 \%$ of participants) and were in governmental institutions ( $69.78 \%$ of participants). The mean and standard deviation of CESD was 18.22 and 10.81, respectively. The mean of the balance score of each aspect of social identity compared to self-identity ranged from 0.83 to 0.88 . Self-assessment of their artistic work was associated with the score of CESD $(\beta=-4.31 ; p$-value $<0.001)$, but assessments by other groups were not statically significant (Supplementary Fig. 1). 
A
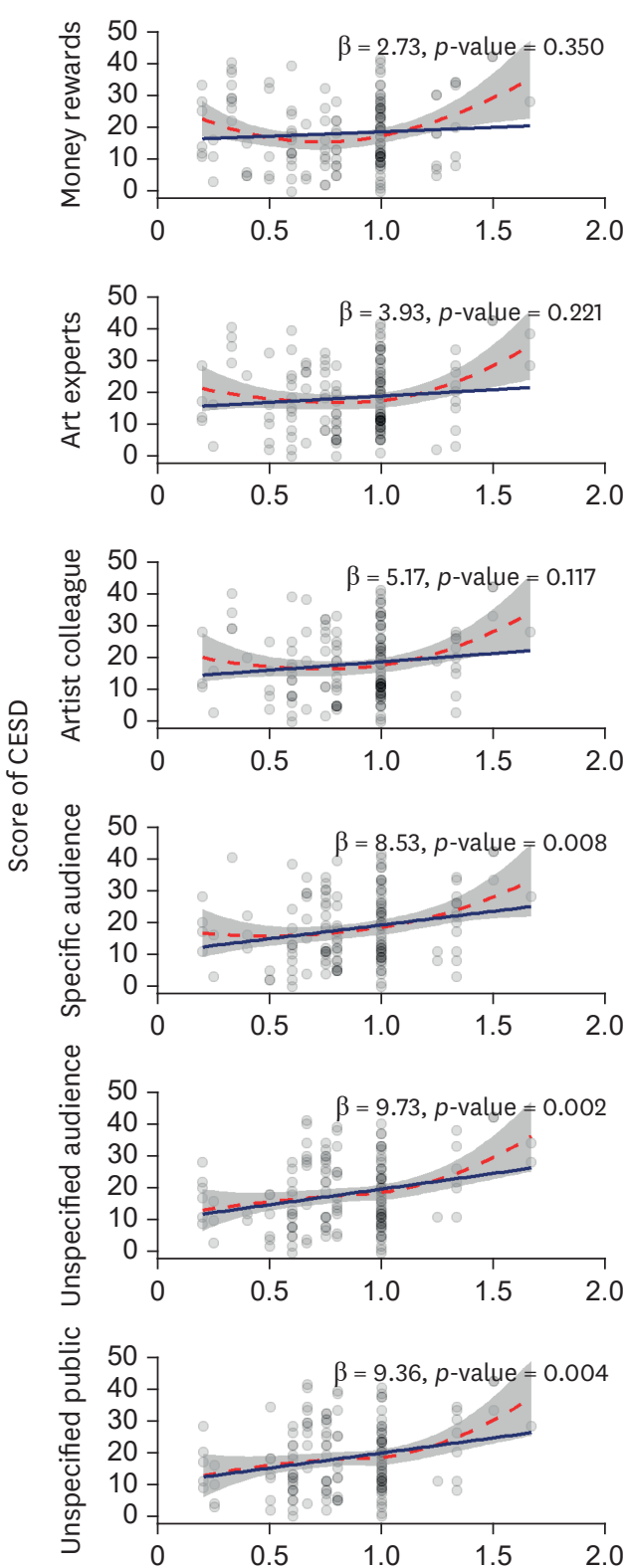

B
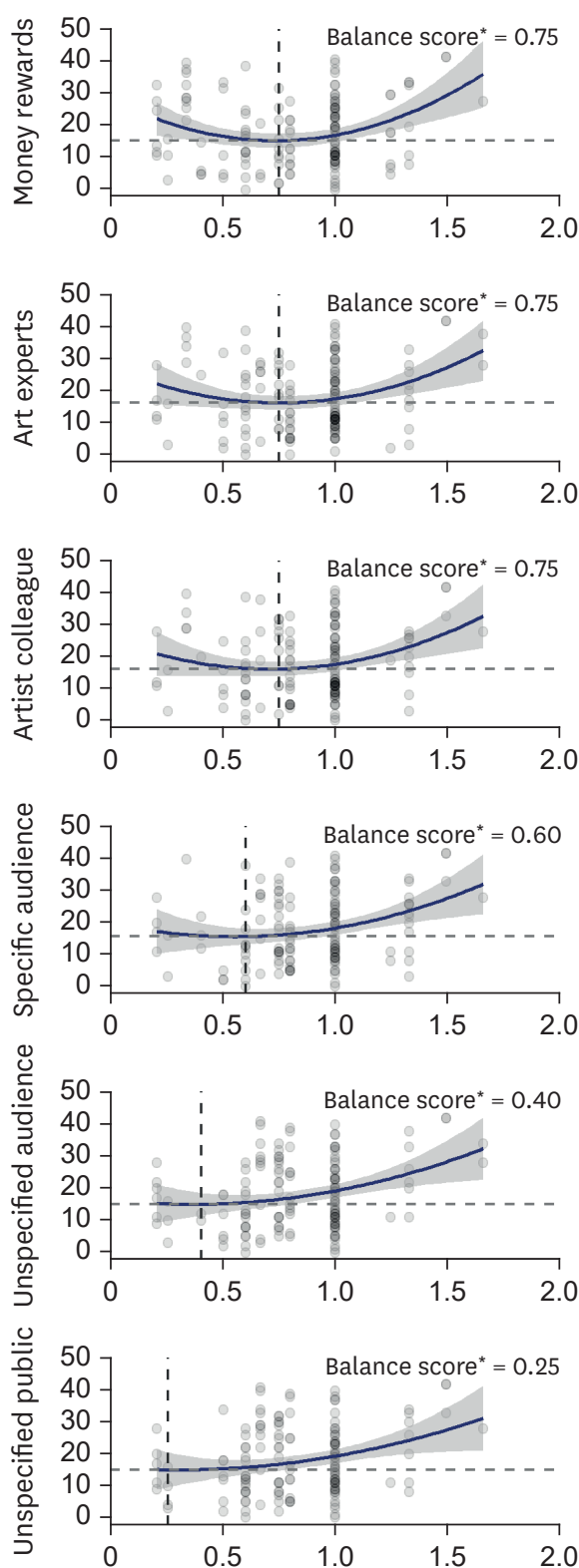

Balance score of social identity to self-identity

Fig. 2. The relationship between balance score of each social-identity compared to self-identity on job value and CESD in dancers. The red dashed line indicates the smooth nonparametric curve using a locally weighted scatterplot smoothing (the lowess span, 1.00) and the grey shadow indicates the 95\% confidence interval of smoothed curve. The navy solid line indicates the linear regression line between balance score and CESD. $\beta$ and $p$-value indicates that linear regression coefficients and its $p$-value, respectively.

CESD: Center for Epidemiologic Studies Depression.

*Indicates that the balance score of social-identity compared to self-identity at the minimum value of CESD in quadratic fitting model.

Results from the ANOVA showed a statistically significant difference in CESD among groups with balance score of identity with respect to specific audience ( $p$-value $=0.030$ ), unspecified audience ( $p$-value $=0.007)$, and unspecified public $(p$-value $=0.020)$. The difference among balance groups was not significant with the respect to money reward ( $p$-value $=0.119)$, art expert $(p$-value $=0.163)$, and artist colleague $(p$-value $=0.095)$ 
Table 1. Basic characteristics of study participants $(n=139)$

\begin{tabular}{|c|c|c|}
\hline Characteristics & Mean \pm standard deviation & No. $(\%)$ \\
\hline Age $^{*}$ & $31.84 \pm 7.35$ & \\
\hline \multicolumn{3}{|l|}{ Sex } \\
\hline Female & & $121(87.05)$ \\
\hline Male & & 18 (12.95) \\
\hline \multicolumn{3}{|l|}{ Education } \\
\hline High school & & $6(4.32)$ \\
\hline College & & $83(59.71)$ \\
\hline Graduate school & & $47(33.81)$ \\
\hline Not responding & & $3(2.16)$ \\
\hline \multicolumn{3}{|l|}{ Marital status } \\
\hline Unmarried & & $77(55.40)$ \\
\hline Married & & $50(35.97)$ \\
\hline Divorced/bereaved/separated & & $1(0.72)$ \\
\hline Not responding & & $11(7.91)$ \\
\hline \multicolumn{3}{|l|}{ Institution } \\
\hline Governmental & & $97(69.78)$ \\
\hline Private & & $22(15.83)$ \\
\hline Freelancer & & $16(11.51)$ \\
\hline No response & & $4(2.88)$ \\
\hline \multicolumn{3}{|l|}{ Type of dancer } \\
\hline Korean & & $126(90.65)$ \\
\hline Other/no response & & $13(9.35)$ \\
\hline CESD score $^{\dagger}$ & $18.22 \pm 10.81$ & \\
\hline \multicolumn{3}{|l|}{ Balance score f $^{\ddagger}$} \\
\hline Money rewards/self & $0.83 \pm 0.32$ & \\
\hline Higher group & & $16(11.51)$ \\
\hline Middle group & & $57(41.01)$ \\
\hline Lower group & & $66(47.48)$ \\
\hline Art experts/self & $0.87 \pm 0.29$ & \\
\hline Higher group & & $14(10.07)$ \\
\hline Middle group & & $62(44.60)$ \\
\hline Lower group & & $63(45.32)$ \\
\hline Artist colleague/self & $0.88 \pm 0.28$ & \\
\hline Higher group & & 15 (10.79) \\
\hline Middle group & & $64(46.04)$ \\
\hline Lower group & & $60(43.17)$ \\
\hline Specific audience/self & $0.88 \pm 0.28$ & \\
\hline Higher group & & 19 (13.67) \\
\hline Middle group & & $52(37.41)$ \\
\hline Lower group & & $68(48.92)$ \\
\hline Unspecified audience/self & $0.83 \pm 0.28$ & \\
\hline Higher group & & $11(7.91)$ \\
\hline Middle group & & $54(38.85)$ \\
\hline Lower group & & $74(53.24)$ \\
\hline Unspecified public/self & $0.83 \pm 0.28$ & \\
\hline Higher group & & $12(8.63)$ \\
\hline Equal group & & $50(35.97)$ \\
\hline Lower group & & $77(55.40)$ \\
\hline
\end{tabular}

${ }^{*}$ One missing value; ${ }^{\dagger}$ The Center for Epidemiologic Studies Depression score; ${ }^{\ddagger}$ Balance score of each social identity compared to self-identity on job value: lower (social identity < self-identity); equal group (social identity = self-identity); higher (social-identity > self-identity).

Fig. 1 presents the CESD according to the balance group of each social identity compared to self-identity based on job value. The mean of CESD is highest in the higher balance group (social-identity > self-identity). Post hoc comparisons of mean CESD scores among balance groups on job value indicate significant differences between higher and lower groups (specific audience: difference $=7.06, p$-value $=0.030$; unspecified audience: difference $=$ 10.49, $p$-value $=0.007$; unspecified public: difference $=9.23, p$-value $=0.016)$. The difference 
of CESD between higher and equal groups was found to be statistically significant with respect to unspecified audience (difference $=10.56, p$-value $=0.008$ ) and unspecified public $($ difference $=8.80, p$-value $=0.029)$

Fig. 2 shows the relationship between the balance score of each social identity compared to self-identity on job value and CESD in dancers. There is a linear relationship between balance score and CESD with respect to specific audience $(\beta=8.53 ; p$-value $=0.008)$, unspecified audience $(\beta=9.73 ; p$-value $=0.002)$, and unspecified public $(\beta=9.36$; $p$-value $=0.004)$. There is no association with respect to any other aspect of social identity. The balance score of money reward, art expert, artist colleague, specific audience, unspecified audience, and unspecified public compared to self-identity at the minimum CESD score in the quadratic fitting model was $0.75,0.75,0.75,0.60,0.40$, and 0.25 , respectively.

Fig. 3 presents the results of piecewise linear regression at the breaking point of 1 in the balance score where social identity is equal to self-identity. In the range of 1 or higher, balance score was associated with CESD with respect to artist colleague $(\beta=12.79 ; p$-value $=$ $0.040)$, unspecified audience $(\beta=21.73$; $p$-value $=0.004)$, and unspecified public $(\beta=18.99$; $p$-value $=0.015)$. We found no significant association between balance score and CESD in the range of 1 or lower of balance score with respect to any social identity.
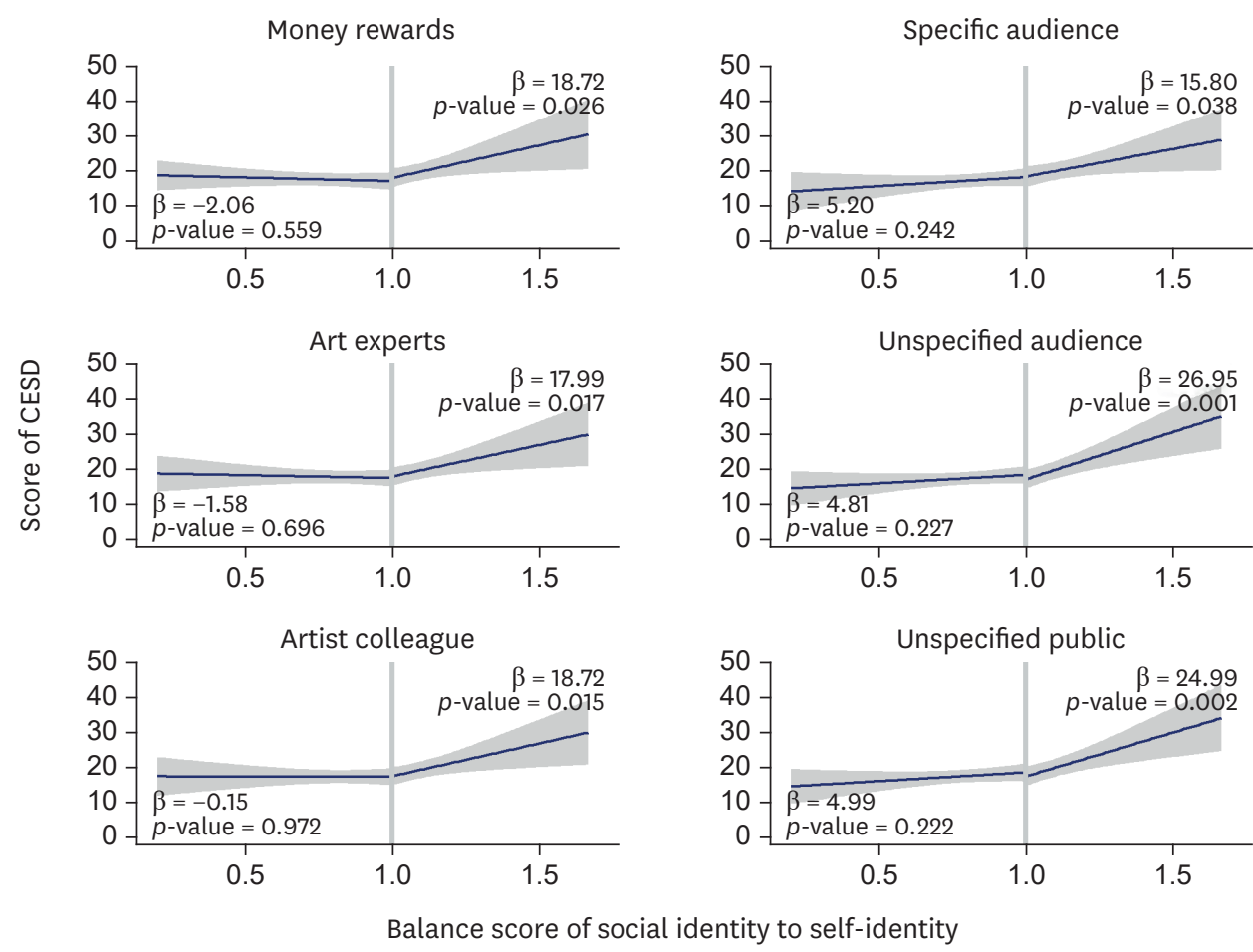

Fig. 3. The results of piecewise linear regression between balance score on job value and CESD at the breaking point of 1 of balance score. The navy solid line indicates the linear regression line between balance score and CESD. CESD: Center for Epidemiologic Studies Depression. 


\section{DISCUSSION}

In the current study, depressive symptoms were aggravated by shifting from self- to social group evaluation of specific audience, unspecified audience, and unspecified public, but not by money reward, art expert, and artist colleague. The optimal balance points were decreased by order of art experts, money rewards, artist colleague, specific audience, unspecified audience, and unspecified public (values are $0.75,0.73,0.71,0.55$, and 0.36 , respectively). If an artist gives art experts' evaluation $75 \%$ more weightage than to his or her own evaluation, the artist may fall into depressive symptoms as per the current study. In the same context, artists should not consider other social evaluations more than the optimal balance points. Among the other social evaluation groups, the weighting of the unspecified public is the most dangerous social evaluative threat. To prevent depressive symptoms, an artist should keep one' valence for the job value by being insensitive to the social evaluation threat and enhance self-identity.

Job value from social group evaluation is one of the social supports comprising social identity. Social identity is a perception of how a self belongs to a certain social group [11]. Social identity has 2 important processes of self-categorization and social comparison. Similarity between self and other in-group members and difference between self and other out-group members help to construct the self-categorization process. Social comparison helps to find a position where self or society is located, using upward and downward comparison, and enhance self-esteem [20]. If one's society for social identity formulation has characters of heterogeneity, is too wide an in-group, and is unpredictable or shaky, selfcategorization and social comparison will not be well-developed, or will sharply fluctuate. For example, social comparison on social media can result in body-image change without actual body shape change, and related mood fluctuation [21]. In the current study, if an artist considers the unspecified public too much as a social in-group, his or her social identity and job value will fluctuate, consequently leading to depressive symptoms.

A well-designed qualitative and quantitative study reported "performance anxiety" in musicians [22]. This means that performance artists are sensitive to an audience's response while engaging with it. Hence, an artist may feel self-conscious when facing numerous types of audiences. In the study, musicians suffer from social phobia (33\%), depressive symptoms (32\%), and even post-traumatic stress disorder $(22 \%)$. These symptoms can be attributed to a mix of social identity and self-identity [22]. Musicians believe that music is life, and musicians cannot do anything else. In this condition, if social identity is damaged by the social evaluation threat, self-identity can also become damaged. Consequently, this leads to depressive symptoms as our current study show.

Performing artists' health is related to physical, psychological, social, and creative domains [23]. For physical problems, a review article summarized the occupational hazards of ballet dancers, occupational and personal stress with low coping skills due to lack of social experience, economic factors, and frequent injuries [24]. Almost $40 \%$ of retired professional ballet dancers suffer from musculoskeletal injuries [25]. As discussed above, most articles report the physical problems of performing artists, but not on the psychological, social, and creative domains. Although a study undertook job stress questionnaires to investigate the psychosocial problem, they used the demand-control-support model of Akel and Duger [26]. The authors reported that performing artists suffer from lack of decision latitude, demands 
of physical exertion and physical load, and lack of job security. Because a job-demand model was created to focus on the manual work, a more detailed analysis was not done in that study.

Our current study tried to investigate performing artists' specific stress of social evaluation to job value, especially those related to the psychological, social, and creative nature of performing arts. However, we cannot find an exact social concept of our current result for a balance score between self-evaluation and other social evaluation. One of the main concepts of the current study is needing a balance between self-identity and social identity on job value. If self-identity of job value is attenuated and social identity of job value is increased, the performing arts can easily lead an artist to depressive symptoms. Such a transit from self-identity to social identity can be observed in computer-mediated communication, and attenuated self-identity brings de-individuation, or the so-called social identity model of the deindividuation effect [27]. However, we think that this is not the same as our current study results. The disturbance between self-identity and social identity on job value is our main research outcome. Further qualitative studies are needed to conventionalize our current study results to prevent depressive symptoms among performing artists.

Our results should be interpreted within the context of the study's limitations. First, the nature of the cross-sectional study design of the current study can lead to misinterpretation of causality. We cannot confirm the causality whether a disturbed balance score between self and social identity on job value is anticipant to depressive symptoms. There is a possibility that depressive symptoms make artists more sensitive to social evaluation. Second, severe depressive symptoms can aggravate turnover intention and retirement from performing arts; hence our current study has the error of the healthy worker effect. We enrolled only dance artists, and hence the study cannot be generalized to all performing arts. Third, this was first attempt to measure the balance score of each aspect of social identity compared to selfidentity on job value. Therefore, this balance score would not be validated by other previous studies. Considering that it is important for artists to keep the balance between self- and social identity to mitigate depressive symptoms, it is worthwhile to introduce this balance score to quantify the balance between self- and social identity.

\section{CONCLUSIONS}

Dance artists should maintain a balance between self-identity and social identity on job value to prevent depressive symptoms. These results are related to performing artists' occupational characteristics of the social and creative domain. Further qualitative study is needed to conventionalize our current study outcome.

\section{ACKNOWLEDGMENTS}

The authors would like to thank all the dancers who participated in our study. 


\section{SUPPLEMENTARY MATERIAL}

\section{Supplementary Fig. 1}

The association of self- and social identity based on job value with CESD in dancers. The navy solid line indicates the linear regression line between the extent of influence on evaluation regarding job value and CESD. $\beta$ and $p$-value indicates that linear regression coefficients and its $p$-value, respectively. The red dashed line indicates the smooth nonparametric curve using a locally weighted scatterplot smoothing loess smoother (the lowess span, 0.75) and the gray shadow indicates the 95\% confidence interval of smoothed curve. In X-axis, 1, 2, 3, 4, 5 indicates "not important," "slightly important," "moderately important," "important," and "very important," respectively.

Click here to view

\section{REFERENCES}

1. Lopez AD, Mathers CD, Ezzati M, Jamison DT, Murray CJ. Global and regional burden of disease and risk factors, 2001: systematic analysis of population health data. Lancet 2006;367(9524):1747-57. PUBMED | CROSSREF

2. Rost KM, Meng H, Xu S. Work productivity loss from depression: evidence from an employer survey. BMC Health Serv Res 2014;14(1):597. PUBMED | CROSSREF

3. Cole MG, Dendukuri N. Risk factors for depression among elderly community subjects: a systematic review and meta-analysis. Am J Psychiatry 2003;160(6):1147-56. PUBMED | CROSSREF

4. Bonde JP. Psychosocial factors at work and risk of depression: a systematic review of the epidemiological evidence. Occup Environ Med 2008;65(7):438-45.

PUBMED | CROSSREF

5. Yoon CG, Bae KJ, Kang MY, Yoon JH. Is suicidal ideation linked to working hours and shift work in Korea? J Occup Health 2015;57(3):222-9. PUBMED | CROSSREF

6. Yoon JH, Jeung D, Chang SJ. Does high emotional demand with low job control relate to suicidal ideation among service and sales workers in Korea? J Korean Med Sci 2016;31(7):1042-8. PUBMED | CROSSREF

7. Yoon JH, Junger W, Kim BW, Kim YJ, Koh SB. Investigating the time lag effect between economic recession and suicide rates in agriculture, fisheries, and forestry workers in Korea. Saf Health Work 2012;3(4):294-7. PUBMED | CROSSREF

8. Yoon JH, Kang MY. The crossover effect of spouses' long working hours on depressive symptoms and suicidal ideation. Ind Health 2016;54(5):410-20. PUBMED | CROSSREF

9. Yoon JH, Won JU, Lee W, Jung PK, Roh J. Occupational noise annoyance linked to depressive symptoms and suicidal ideation: a result from nationwide survey of Korea. PLoS One 2014;9(8):e105321. PUBMED | CROSSREF

10. Kyaga S, Landén M, Boman M, Hultman CM, Långström N, Lichtenstein P. Mental illness, suicide and creativity: 40-year prospective total population study. J Psychiatr Res 2013;47(1):83-90. PUBMED | CROSSREF

11. Stets JE, Burke PJ. Identity theory and social identity theory. Soc Psychol Q 2000;63(3):224-37. CROSSREF

12. Takahashi Y, Uchida C, Miyaki K, Sakai M, Shimbo T, Nakayama T. Potential benefits and harms of a peer support social network service on the internet for people with depressive tendencies: qualitative content analysis and social network analysis. J Med Internet Res 2009;11(3):e29. PUBMED | CROSSREF

13. Mead GH. The social self. Psychiatry 1978;41(2):178-82. CROSSREF 
14. Denson TF, Creswell JD, Granville-Smith I. Self-focus and social evaluative threat increase salivary cortisol responses to acute stress in men. J Behav Med 2012;35(6):624-33. PUBMED | CROSSREF

15. Gruenewald TL, Kemeny ME, Aziz N, Fahey JL. Acute threat to the social self: shame, social self-esteem, and cortisol activity. Psychosom Med 2004;66(6):915-24. PUBMED | CROSSREF

16. Haikal M, Hong RY. The effects of social evaluation and looming threat on self-attentional biases and social anxiety. J Anxiety Disord 2010;24(3):345-52.

PUBMED | CROSSREF

17. Morris MC, Rao U, Garber J. Cortisol responses to psychosocial stress predict depression trajectories: social-evaluative threat and prior depressive episodes as moderators. J Affect Disord 2012;143(1-3):223-30. PUBMED | CROSSREF

18. Radloff LS. The CES-D scale: a self-report depression scale for research in the general population. Appl Psychol Meas 1977;1(3):385-401. CROSSREF

19. R Core Team. R: a language and environment for statistical computing. Vienna: R Foundation for Statistical Computing; 2013.

20. Redersdorff S, Martinot D. Impact of upward and downward social comparisons on self-esteem: importance of activated identity. Annee Psychol 2003;103(3):411-44. CROSSREF

21. Fardouly J, Diedrichs PC, Vartanian LR, Halliwell E. Social comparisons on social media: the impact of Facebook on young women's body image concerns and mood. Body Image 2015;13:38-45. PUBMED | CROSSREF

22. Ackermann BJ, Kenny DT, O'Brien I, Driscoll TR. Sound practice-improving occupational health and safety for professional orchestral musicians in Australia. Front Psychol 2014;5:973. PUBMED | CROSSREF

23. Manchester RA. Measuring the health of performing artists. Med Probl Perform Art 2008;23(3):91-2.

24. Kelman BB. Occupational hazards in female ballet dancers. Advocate for a forgotten population. AAOHN J 2000;48(9):430-4. PUBMED | CROSSREF

25. Smith TO, de Medici A, Oduoza U, Hakim A, Paton B, Retter G, et al. National survey to evaluate musuloskeletal health in retired professional ballet dancers in the United Kingdom. Phys Ther Sport 2017;23:82-5. PUBMED | CROSSREF

26. Akel S, Duger T. Psychosocial risk factors of musicians in Turkey - use of the job content questionnaire. Med Probl Perform Art 2007;22(4):147-52.

27. Vilanova F, Beria FM, Costa AB, Koller SH. Deindividuation: from Le Bon to the social identity model of deindividuation effects. Cogent Psychol 2017;4(1):1308104. 